\title{
Thermodynamic Properties of Light Synthetic Natural Gas Mixtures Using the RK-PR Cubic Equation of State
}

\author{
Santiago Aparicio Martinez* and Kenneth R. Hall \\ Artie McFerrin Department of Chemical Engineering \\ Texas A\&M University \\ College Station, TX 77843, USA
}

\begin{abstract}
*Corresponding author; permanent address: Department of Chemistry, University of Burgos, 09001 Burgos, Spain. Phone: +34 947258 062; Fax: +34 947258 831; e-mail: sapar@ubu.es
\end{abstract}

Supporting Information 


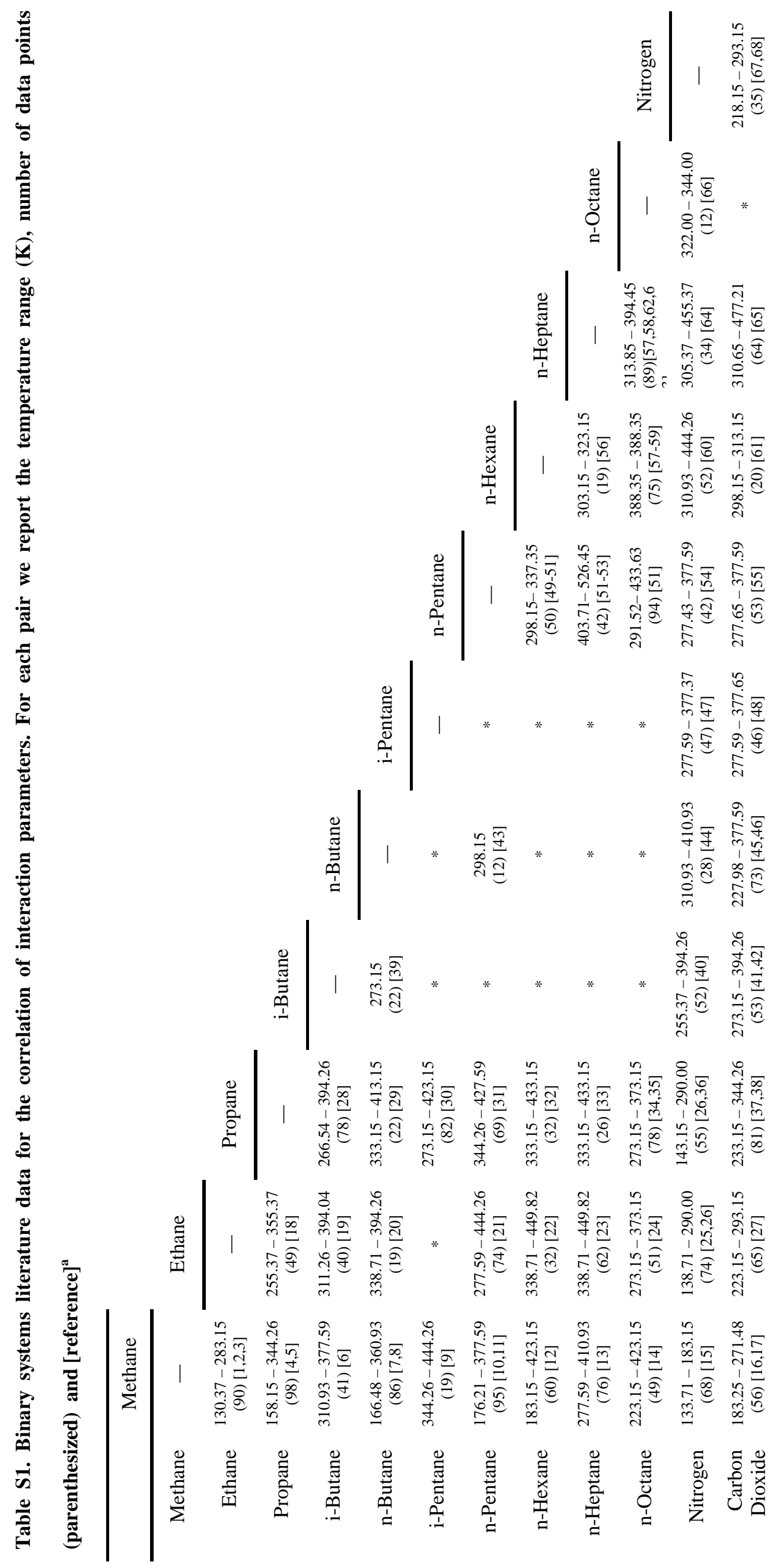




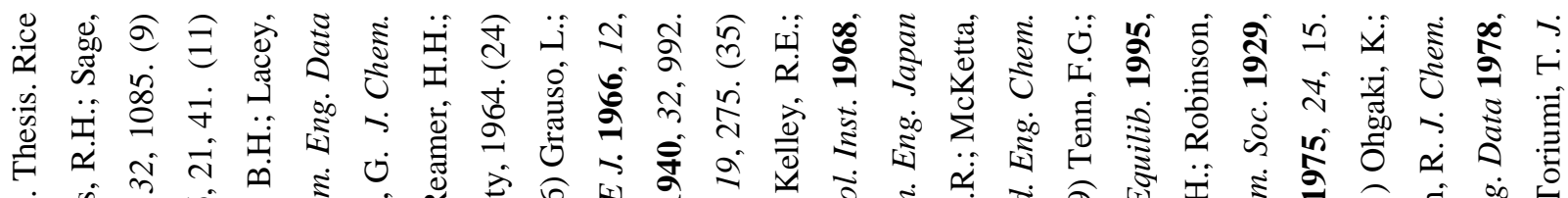

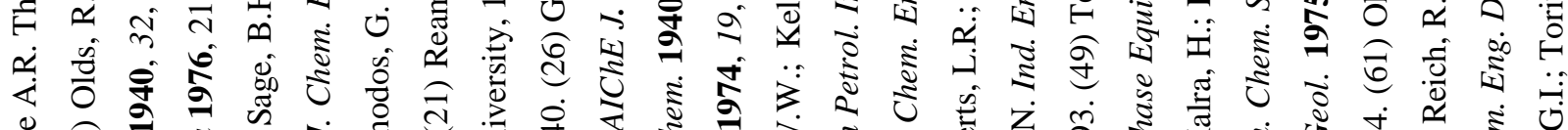

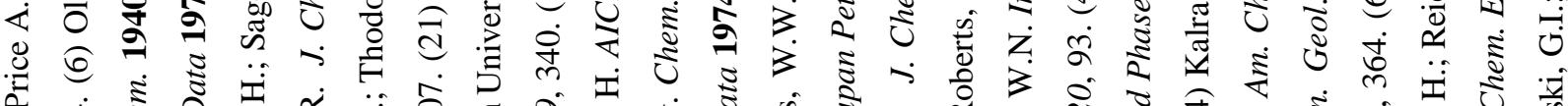

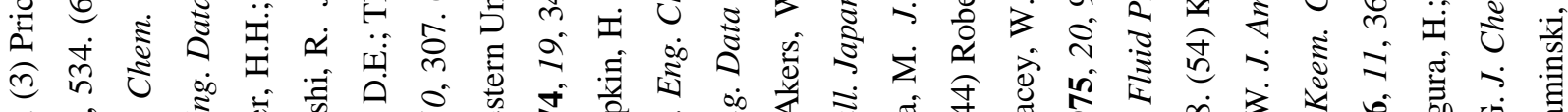

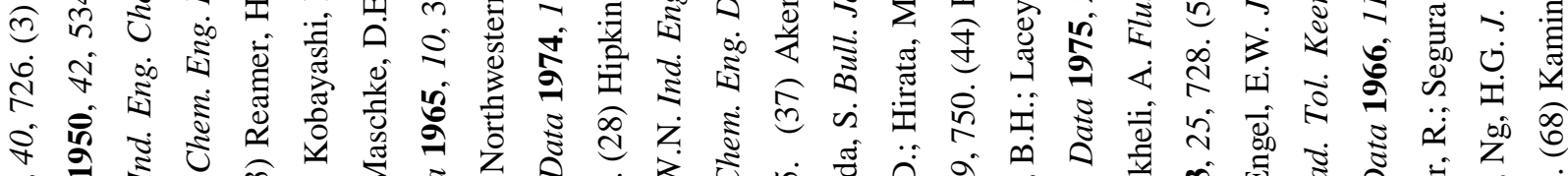

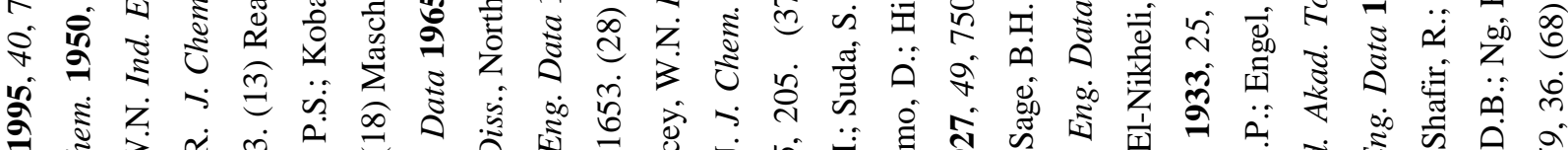

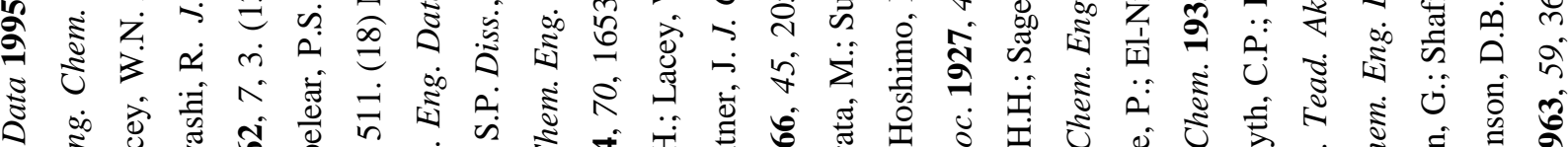

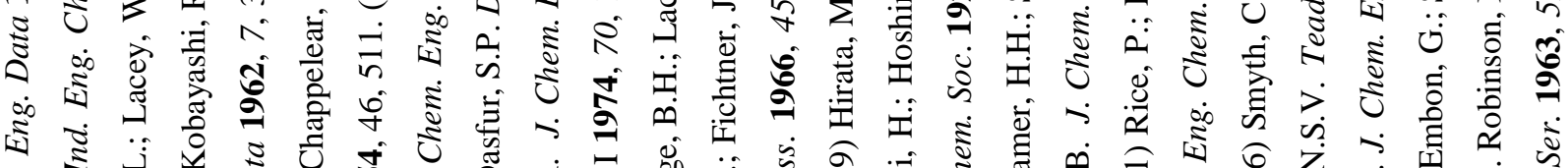

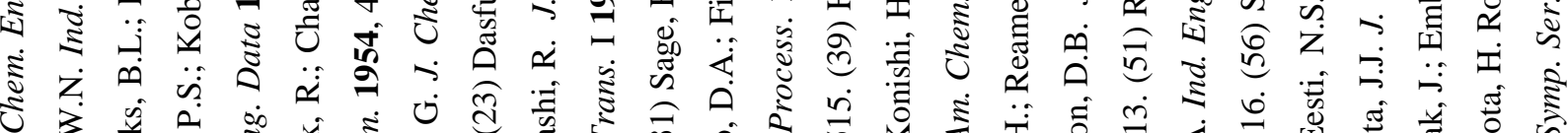

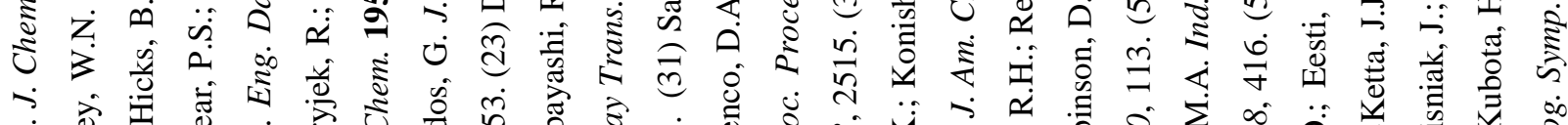

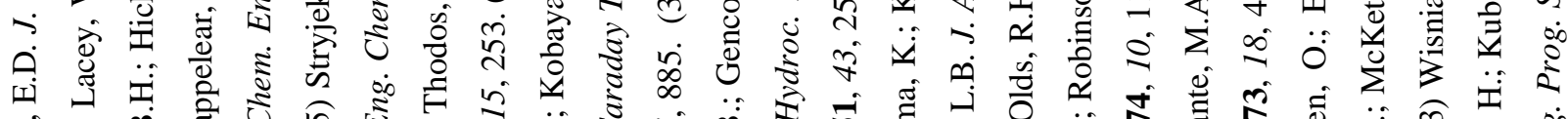

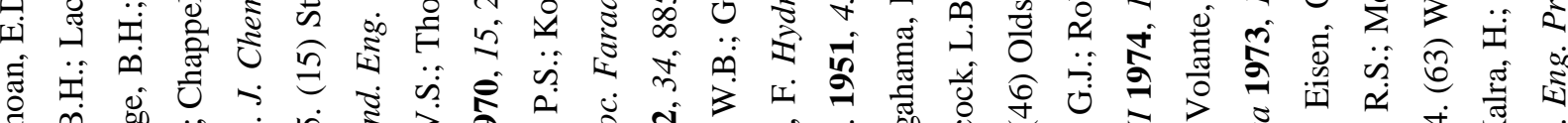

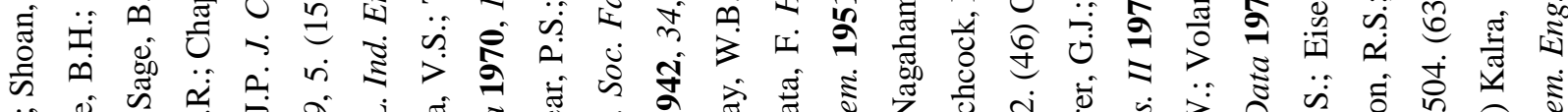

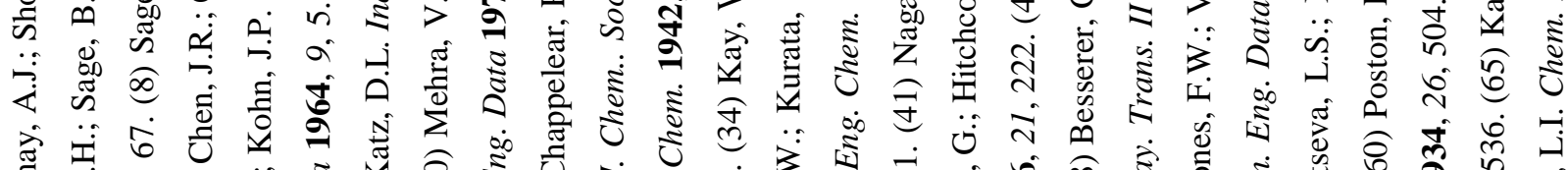

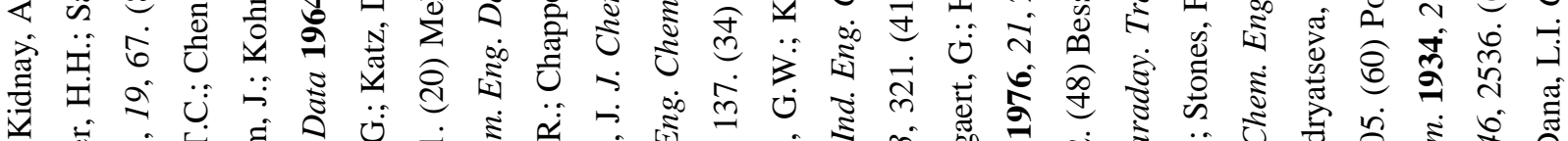

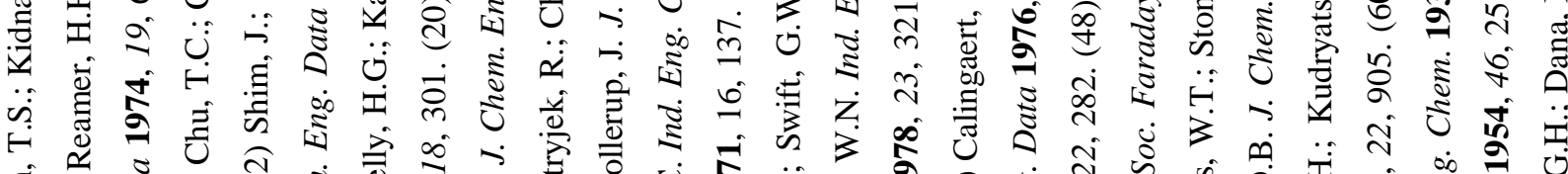
药

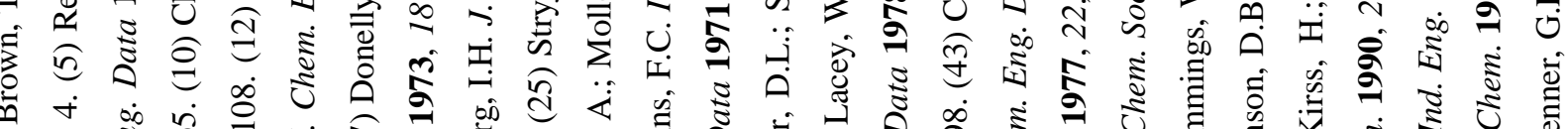

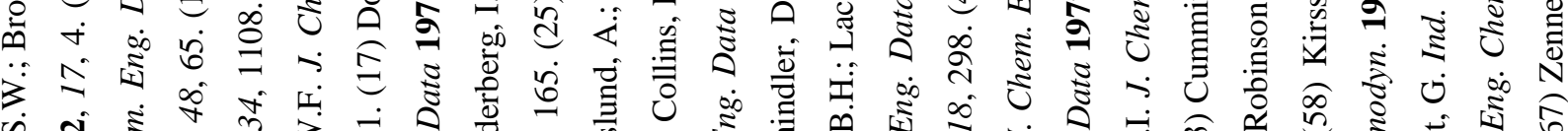

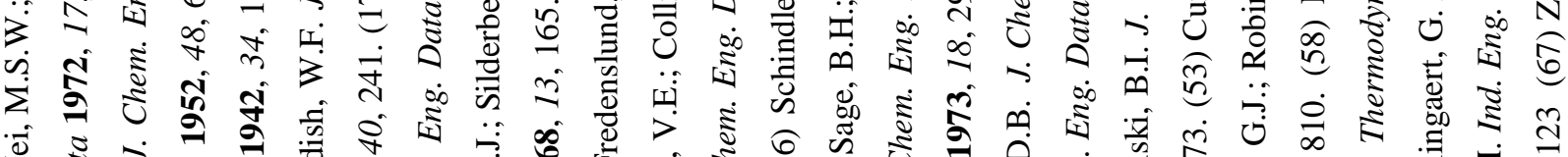

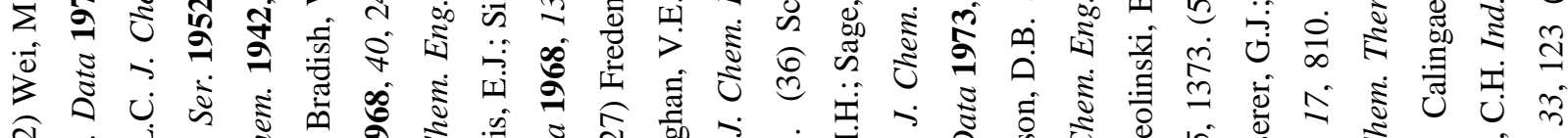
बิ

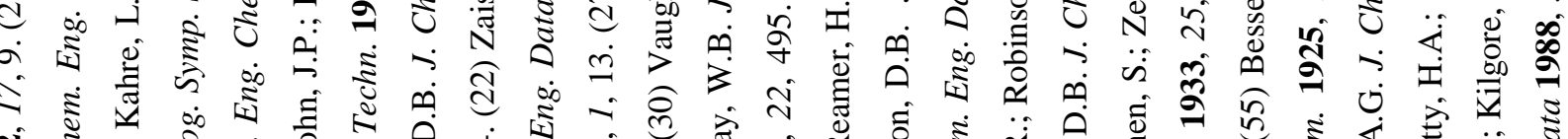

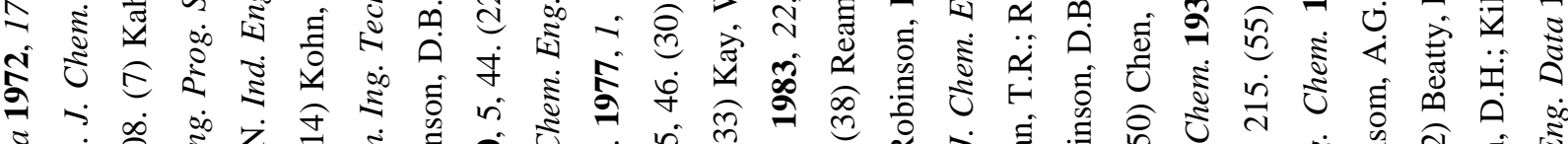

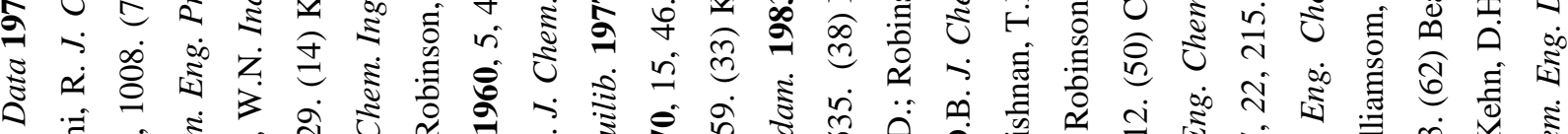

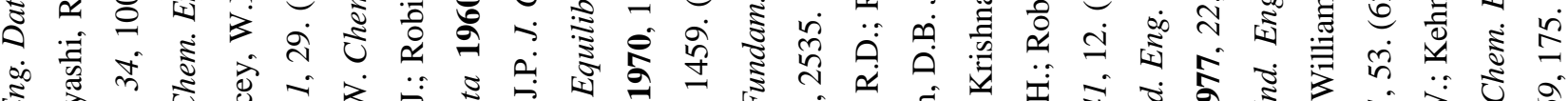

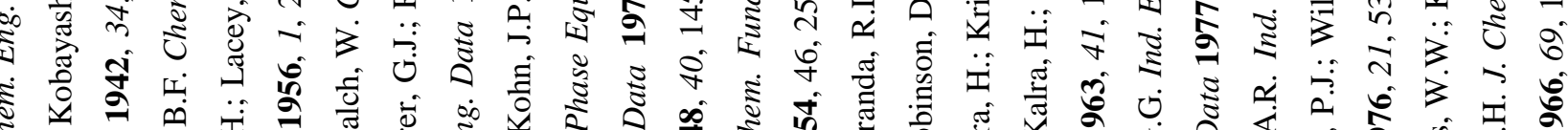

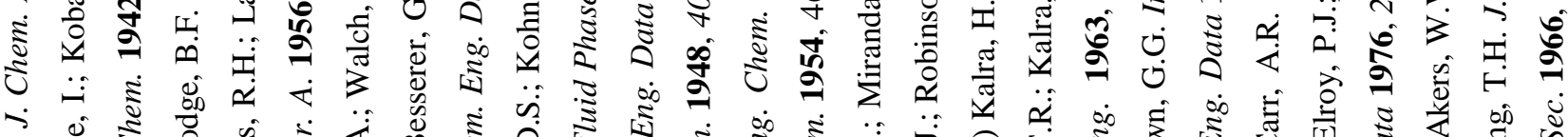

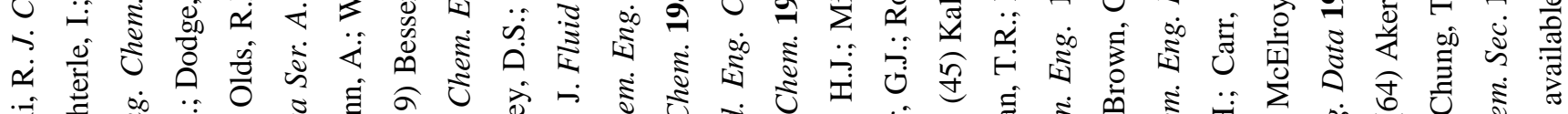

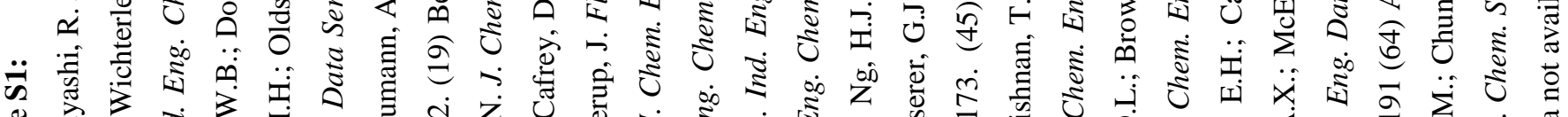

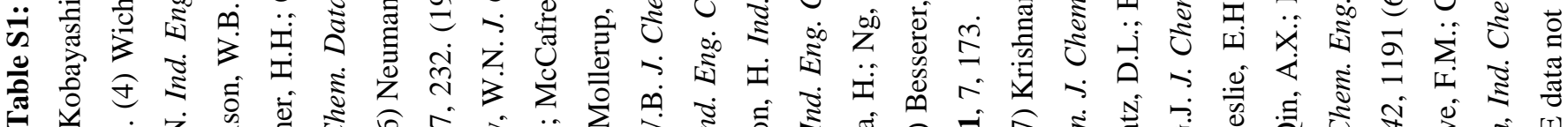

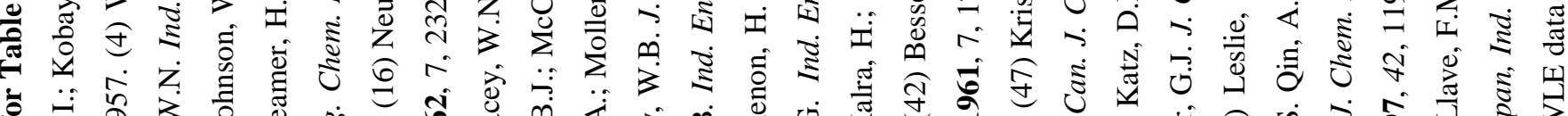

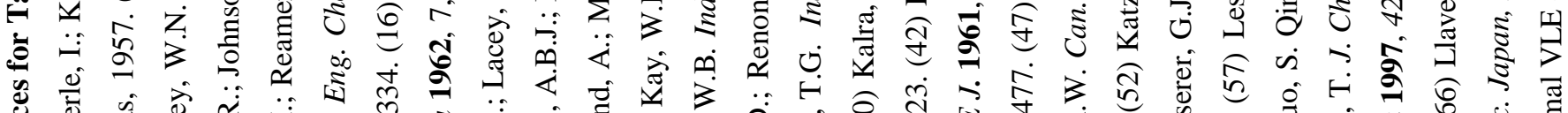

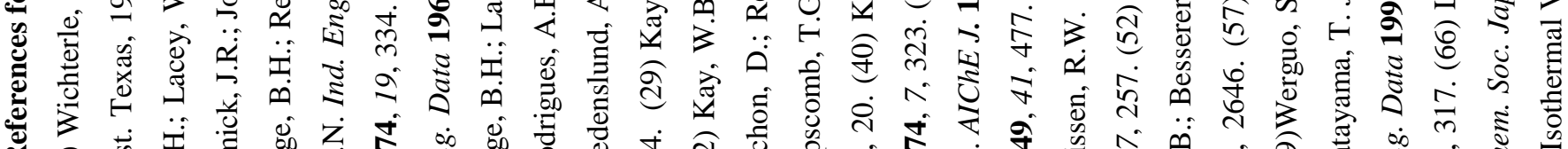

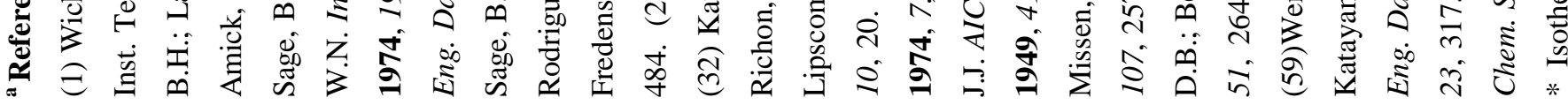




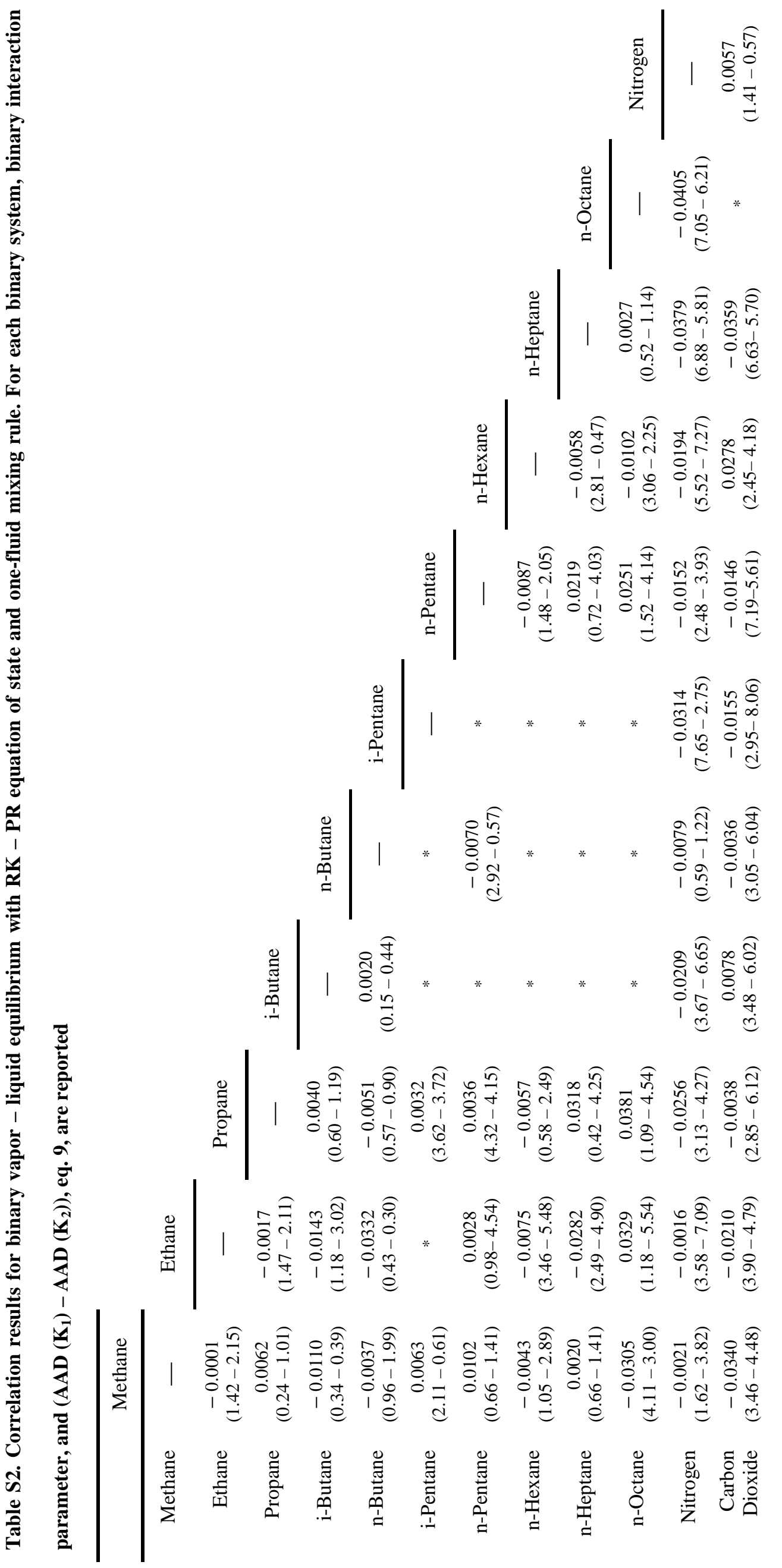

